\title{
Nutrition Knowledge and Self-Efficacy Among Classroom Teachers From a Large Urban School District in Los Angeles County
}

\author{
Janni Kinsler ${ }^{1}$, Wendelin Slusser ${ }^{1}$, Jennifer Toller Erausquin ${ }^{2}$, Chan Le Thai ${ }^{3}$, Michael Prelip ${ }^{1}$ \\ ${ }^{1}$ University of California, Los Angeles \\ ${ }^{2}$ Duke University \\ ${ }^{3}$ University of California, Santa Barbara
}

\begin{abstract}
Purpose: School teachers play a critical role in providing nutrition information to students. Yet, in order for teachers to be a valuable source of nutrition information, they must be equipped with adequate knowledge to be able to convey accurate information to students. The purpose of this study was to assess nutrition-related knowledge and self-efficacy of teachers from a large urban school district in Los Angeles County. Methods: Using a convenience sample, 59 teachers from six elementary schools completed a one time only questionnaire assessing knowledge of food groups and self-efficacy to implement nutrition activities in the classroom. Differences in teachers' responses to questions on knowledge and self-efficacy by demographics were also assessed. Results: The overall mean nutrition knowledge and self-efficacy scores were $50.4 \%$ and $71.4 \%$ respectively. Differences in nutrition knowledge and self-efficacy by demographic characteristics were observed. Conclusion: This study demonstrates that teachers in our sample did not have adequate levels of nutrition knowledge, and may not have possessed the necessary skills to effectively deliver nutrition education to their students. Current efforts to train and educate teachers on nutrition are perhaps falling short of the level needed to effect change in students' dietary behaviors.
\end{abstract}

(C) 2012 Californian Journal of Health Promotion. All rights reserved.

Keywords: teacher nutrition knowledge, teacher nutrition self-efficacy, school-based nutrition programs, fruit and vegetable consumption

\section{Introduction}

Teachers often play a key role in providing nutrition information to students in school based programs (Rafiroiu \& Evans, 2005; PerezRodrigo et al., 2001). Studies have noted that if teachers are expected to add health and nutrition to their repertoire, they must be adequately trained and motivated (Resnicow, Cherry, \& Cross, 1993; Chen et al., 2009). Few published studies have assessed school teachers' nutrition knowledge. Yet, in order for teachers to be a valuable source of nutrition information, they must be equipped with adequate knowledge, and they must be able to convey accurate nutrition information to students and respond to their questions and concerns about diet and nutrition
(Chen et al., 2009). The few U.S.-based studies that have assessed teachers' nutrition-based knowledge found that teachers had fair levels of nutrition knowledge (Rafiroiu \& Evans, 2005; Martin, Hoover, Fox, Lan, \& Ahmad, 1998; Soliah, Newell, Vaden, \& Dayton, 1983). A study in South Carolina found that teachers correctly answered $63.2 \%$ of the questions asked in the knowledge scale (Rafiroiu \& Evans, 2005). Mean nutrition knowledge scores in studies among teachers from Texas and Kansas were $60 \%$ and $70 \%$ respectively (Martin et al., 1998; Soliah et al., 1983).

The Nutrition Friendly Schools and Communities (NFSC) Group at the UCLA School of Public of Health worked with the Los 
Angeles Unified School District (LAUSD) to evaluate various components of their nutrition education efforts. LAUSD is the second largest school district in the U.S. and includes 885 schools, employs over 75,000 teachers, and enrolls approximately 700,000 students each year. LAUSD administers its main nutrition education programs through the Network for a Healthy California - LAUSD (NetworkLAUSD), which was established in 2000 to encourage fruit and vegetable (FV) consumption and physical activity among students. Over the years, the collaborative evaluation studies have focused on different aspects of NetworkLAUSD programming. The primary goal of these evaluation studies has been to determine if students' consumption of FV increased as a result of participating in nutrition education activities. Unfortunately, the results of these studies have consistently found a lack of increase in students FV consumption (Prelip et al., 2011). This prompted the Network-LAUSD to focus on evaluation activities that assessed teachers' nutrition knowledge, as it is possible that the level of knowledge of the teachers delivering the nutrition information may be less than adequate.

\section{Purpose}

The purpose of this pilot descriptive study was to assess nutrition-related knowledge and selfefficacy of LAUSD teachers, and whether teachers responses to these two outcomes differed by demographic characteristics.

\section{Methods}

\section{Study Design and Sample}

Participants were 59 teachers from the six Network-LAUSD elementary schools, a convenience sample recruited by NetworkLAUSD staff in the fall of 2009. NetworkLAUSD schools are defined as schools where $50 \%$ or more of their students are eligible to receive free or reduced priced meals from the National School Meal program and that are participating in Network-LAUSD nutrition education activities. School sites were selected based on expressed interest to participate in the study and availability of teachers and space to administer the questionnaires. Participation of schools and of teachers was voluntary. The study was approved by the UCLA Institutional Review Board and the LAUSD Research and Planning Division.

Teachers completed questionnaires during the Fall Semester (October-December 2009). The questionnaire took approximately 30 minutes to complete. It was administered by a NFSC staff member in a group setting during a regularly scheduled teachers meeting. All participating teachers received classroom resources (value $\leq$ $\$ 5.00)$ after the questionnaire was administered.

\section{Measures}

The teacher questionnaire included three sections assessing teachers' knowledge, selfefficacy, and demographic characteristics. Questions were adapted from the educational materials given to teachers as part of the Network-LAUSD nutrition intervention programs, and were meant to assess the information teachers were expected to teach to students. The items from the educational materials have not been validated elsewhere.

The first section measured teachers' knowledge about food groups and FV servings using eight questions including the following: "Which of the following are food groups according to MyPyramid (grains/vegetables/fruits/milk/meat \& beans/all of the above)?," "How much of your total amount of grains should be "whole grains" (one half/one third/one fourth)?," "In the MyPyramid graphic, the steps and the person climbing them represent (balance/activity/ moderation/variety)," "Eating a healthy breakfast can improve your students' attention, attendance, and academic achievement (true/false)?," "A person that is lactose intolerant cannot eat any dairy products (true/false)," "According to MyPyramid, how many cups of fruit should your students eat each day (1 cup/1 $1 / 2$ cups $/ 2$ cups $/ 2 \quad 1 / 2$ cups)?," "According to MyPyramid, how many cups of vegetables should your students eat each day (1 cup/ $1 \frac{1}{2}$ cups $/ 2$ cups $/ 21 / 2$ cups)?," and "According to MyPyramid, how many ounces of grain products should your students eat each day (3/4/5/ or 6$)$ ?" The second section assessed teachers' selfefficacy to implement nutrition activities in the 
classroom using five questions, each beginning with, "I know how to..." followed by, "read and interpret a food label," "teach my students about reading food labels," "find materials I need to teach my students about nutrition," "teach my students about nutrition," and "incorporate lessons about nutrition into my daily instruction." Response categories were based on a 5-point Likert scale and included strongly agree/ agree/neutral/disagree/strongly disagree. For purposes of the bivariate analyses assessing the association between self-efficacy and demographic characteristics (which were dichotomous or categorical), response categories were dichotomized (high self-efficacy/low selfefficacy). This also allows for the comparison of the outcome variable with each category of the demographic variables. The third section assessed demographic characteristics, including gender, grade taught $\left(\mathrm{K}-2 / 3^{\text {rd }}-5^{\text {th }}\right)$, race/ethnicity (Hispanic or Latino/White/Asian/other), and years of experience as a teacher $\left(\mathrm{K}-2 / 3^{\text {rd }}-5^{\text {th }}\right)$.

\section{Data Analysis}

Univariate analyses were used to assess measures of nutrition-related knowledge and self-efficacy. Logistic regression analyses were used to assess the unadjusted bivariate association between demographic characteristics and nutrition-based knowledge and self-efficacy. Given this was a pilot study with a small sample size, unadjusted models were used to assess the association between demographics and outcome variables rather than adjusted models. All analyses were conducted using Stata 10.0 (Stata Corp, College Station, TX, 2009).

\section{Results}

\section{Demographic Characteristics}

The majority of teachers were female (81\%), $25 \%$ taught K-2 and $75 \%$ taught $3^{\text {rd }}$ through $5^{\text {th }}$ graders. Over half were Hispanic/Latino (56\%), $31 \%$ were White, and $13 \%$ were Asian. Sixty- three percent of teachers had $>11$ years of teaching experience while $37 \%$ had $<=10$ years of experience.

\section{Knowledge about food groups and FV servings}

Frequencies for teachers' correct responses to questions on nutrition knowledge are presented in Table 1. The overall mean nutrition knowledge score was $50.4 \%$. Scores ranged from a low of $16 \%$ to a high of $100 \%$. While all teachers $(100 \%)$ selected the correct answer to the question on the importance of eating breakfast, only $16 \%$ of teachers selected the correct answer to the question on daily recommended servings of fruit. Bivariate associations between nutrition knowledge and demographic characteristics revealed teachers of Hispanic race/ethnicity were less likely than White teachers to correctly identify the definition of lactose intolerance $(p<0.05)$

\section{Self-efficacy to implement nutrition activities in the classroom}

Frequencies for teacher's perceived self-efficacy to implement nutrition activities in the classroom are presented in Table 2. Perceived levels of self-efficacy ranged from a low of $66 \%$ for ability to teach students about reading food labels to a high of $79 \%$ for ability to find materials to teach students about nutrition.

Bivariate associations between self-efficacy and demographic characteristics revealed teachers of Hispanic race/ethnicity were less likely than teachers of White race/ethnicity to know how to teach students about reading food labels $(\mathrm{p}<0.05)$. Teachers with 11-15 years of experience were less likely than teachers with $>16$ years of experience to know how to read and interpret a food label $(\mathrm{p}<0.05)$, teach students about reading food labels $(\mathrm{p}<0.01)$, and teach students about nutrition $(\mathrm{p}<0.05)$ 


\section{Table 1}

Unadjusted odds ratios (UOR) for assessing the bivariate association between teachers' knowledge regarding food groups and daily recommended

servings of FV and demographic characteristics; and percentage of correct responses to nutrition knowledge items for total sample (Total $\mathrm{N}=59$ ).

\begin{tabular}{|c|c|c|c|c|c|c|c|}
\hline $\begin{array}{l}\text { Correct knowledge } \\
\text { about: }\end{array}$ & $\begin{array}{l}\text { Food groups } \\
\text { (MyPyramid) }\end{array}$ & $\begin{array}{l}\text { MyPyramid } \\
\text { graphic }\end{array}$ & $\begin{array}{l}\text { Lactose } \\
\text { intolerant }\end{array}$ & $\begin{array}{l}\text { Servings of } \\
\text { whole grains }\end{array}$ & Servings of fruit & $\begin{array}{l}\text { Servings of } \\
\text { vegetables }\end{array}$ & $\begin{array}{l}\text { Servings of } \\
\text { grain products }\end{array}$ \\
\hline $\begin{array}{l}\text { Demographics } \\
\text { (Reference group) }\end{array}$ & UOR $(95 \%$ CI) & UOR (95\% CI) & UOR (95\% CI) & UOR $(95 \%$ CI $)$ & UOR $(95 \%$ CI $)$ & UOR (95\% CI) & UOR $(95 \% \mathrm{CI})$ \\
\hline \multicolumn{8}{|l|}{ Gender (Female) } \\
\hline Male & $0.93(0.94-9.25)$ & $0.61(0.12-3.24)$ & $0.26(0.51-1.34)$ & $2.12(0.51-7.99)$ & $0.48(0.05-4.25)$ & $1.87(0.46-7.60)$ & $0.99(0.25-3.88)$ \\
\hline $\begin{array}{l}\text { Grade taught }\left(3^{\text {rd }}-5^{\text {th }}\right) \\
\text { K-2 }\end{array}$ & $0.69(0.07-6.78)$ & $0.41(0.10-1.59)$ & $0.58(0.17-1.96)$ & $0.72(0.21-2.49)$ & $1.31(0.24-7.23)$ & $0.45(0.12-1.72)$ & $0.23(0.04-1.14)$ \\
\hline $\begin{array}{l}\text { Race/ethnicity } \\
\text { (White) }\end{array}$ & -------- & $0.70(0.18-2.72)$ & $0.26(0.07-0.90)^{*}$ & $1.73(0.49-6.13)$ & $1.88(0.33-10.5)$ & $0.26(0.05-1.25)$ & $0.57(0.16-2.04)$ \\
\hline $\begin{array}{l}\text { Hispanic } \\
\text { Asian }\end{array}$ & -------- & $0.37(0.03-3.91)$ & $0.41(0.07-2.47)$ & $1.20(0.16-8.70)$ & $1.50(0.11-20.3)$ & $2.40(0.36-16.2)$ & $0.83(0.11-6.11)$ \\
\hline \multicolumn{8}{|l|}{$\begin{array}{l}\text { Years of teaching } \\
\text { experience }(16+)\end{array}$} \\
\hline $11-15$ & $0.75(0.04-13.0)$ & $0.43(0.09-2.03)$ & $0.25(0.06-1.16)$ & $3.58(0.90-14.2)$ & $1.46(0.18-11.7)$ & $0.46(0.10-2.17)$ & $0.67(0.17-2.67)$ \\
\hline $6-10$ & $0.28(0.02-3.39)$ & $0.62(0.13-3.06)$ & $1.28(0.32-5.13)$ & $0.14(0.01-1.25)$ & $5.93(0.95-37.2)$ & $0.17(0.02-1.56)$ & $0.34(0.08-1.45)$ \\
\hline $0-5$ & $0.35(0.02-6.37)$ & $0.27(0.03-2.61)$ & $0.88(0.18-4.23)$ & $0.98(0.18-5.23)$ & --------- & $2.00(0.38-10.5)$ & $1.20(0.19-7.70)$ \\
\hline Total Sample ${ }^{* *}$ N & $53(91)$ & $14(25)$ & $24(41)$ & $23(40)$ & $9(16)$ & $15(26)$ & $37(64)$ \\
\hline
\end{tabular}

Note 1. Since $100 \%$ of teachers correctly answered the question on the importance of eating breakfast, there was no variation in this outcome variable when comparing it with the demographics for the bivariate logistic regression analysis thus the results are not presented.

Note 2. For purposes of the bivariate analyses assessing the association between knowledge and demographic characteristics, response categories were dichotomized so that $1=$ correct response and $0=$ incorrect response.

p $<<0.05$

*** Overall mean nutrition score $=50.4 \%$. 


\section{Table 2}

Unadjusted odds ratios (UOR) for assessing the bivariate association between teachers' perceived high self-efficacy to implement nutrition activities in the classroom and demographic characteristics; and percentage of teachers reporting high levels of self-efficacy for total sample (Total

\begin{tabular}{|c|c|c|c|c|c|}
\hline I know how to: & $\begin{array}{l}\text { Read and interpret a } \\
\text { food label }\end{array}$ & $\begin{array}{l}\text { Teach students about } \\
\text { reading food labels }\end{array}$ & $\begin{array}{l}\text { Find materials to teach } \\
\text { students about } \\
\text { nutrition }\end{array}$ & $\begin{array}{l}\text { Teach students about } \\
\text { nutrition }\end{array}$ & $\begin{array}{l}\text { Incorporate lessons } \\
\text { about nutrition in } \\
\text { daily instruction }\end{array}$ \\
\hline $\begin{array}{l}\text { Demographics } \\
\text { (Reference group) }\end{array}$ & UOR $(95 \%$ CI) & $\mathrm{UOR}(95 \% \mathrm{CI})$ & UOR $(95 \% \mathrm{CI})$ & $\mathrm{UOR}(95 \% \mathrm{CI})$ & $\operatorname{UOR}(95 \% \mathrm{CI})$ \\
\hline \multicolumn{6}{|l|}{ Gender (Female) } \\
\hline Male & $0.99(0.23-4.32)$ & $1.46(0.34-6.25)$ & $1.22(0.23-6.55)$ & $1.10(0.25-4.75)$ & $0.80(0.20-3.14)$ \\
\hline \multicolumn{6}{|l|}{ Grade taught $\left(3^{\text {rd }}-5^{\text {th }}\right)$} \\
\hline $\mathrm{K}-2$ & $0.66(0.16-2.79)$ & $2.42(0.70-8.39)$ & $0.23(0.03-2.00)$ & $0.86(0.23-3.27)$ & $1.34(0.37-4.85)$ \\
\hline \multicolumn{6}{|l|}{ Race/ethnicity (White) } \\
\hline Hispanic & $0.21(0.04-1.09)$ & $0.14(0.03-0.73)^{*}$ & $1.28(0.31-5.37)$ & $0.39(0.09-1.66)$ & $2.17(0.64-7.42)$ \\
\hline Asian & -------- & $0.80(0.06-10.6)$ & $1.54(0.14-17.3)$ & $0.54(0.07-4.20)$ & $2.22(0.33-14.8)$ \\
\hline \multicolumn{6}{|l|}{$\begin{array}{l}\text { Years of teaching } \\
\text { experience }(16+)\end{array}$} \\
\hline $11-15$ & $0.18(0.04-0.80)^{*}$ & $0.10(0.02-0.49)^{* *}$ & $0.71(0.15-3.40)$ & $0.17(0.03-0.80)^{*}$ & $0.40(0.10-1.64)$ \\
\hline $6-10$ & $2.82(0.28-28.5)$ & $0.27(0.05-1.40)$ & $1.29(0.20-8.31)$ & $0.56(0.09-3.29)$ & $0.70(0.15-3.31)$ \\
\hline $0-5$ & $0.82(0.12-5.57)$ & $0.58(0.08-4.27)$ & $0.71(0.10-4.89)$ & $0.33(0.05-2.12)$ & $0.63(0.11-3.46)$ \\
\hline Total Sample ${ }^{* * *} \mathrm{~N}(\%)$ & $43(73)$ & $39(66)$ & $46(79)$ & $42(71)$ & $40(68)$ \\
\hline
\end{tabular}




\section{Discussion}

Overall mean nutrition knowledge and selfefficacy scores were $50.4 \%$ and $71.4 \%$ respectively. This study demonstrates that teachers in our sample did not have adequate levels of nutrition knowledge, and may not have possessed the necessary skills to effectively deliver nutrition education to their students. The results of this study make an important contribution to the small body of literature assessing school teachers' knowledge of nutrition, and are particularly relevant given the current emphasis on using school teachers to provide nutrition education to their students in an attempt to impact childhood obesity.

On average, teachers answered correctly approximately half of the eight questions on nutrition knowledge. This score is somewhat lower than in the few existing studies assessing school teachers nutrition knowledge where the overall mean nutrition scores were 60\% (Martin et al., 1998), 63.2\% (Rafiroiu \& Evans, 2005), and $70 \%$ (Soliah et al., 1983). The discrepancy in findings may be a result of using different instruments to assess nutrition knowledge, differences in nutrition education programs being offered to teachers, or individual differences in teachers' levels of nutrition knowledge. Teachers in our sample had very low levels of knowledge about the correct daily servings of food groups, especially for fruit (16\%) and vegetables (26\%). Given that the focus of many school-based programs is to increase FV consumption (Prelip et al., 2011; Heim, Stang, \& Ireland, 2009; David, Cullen, Watson, Konarik, \& Radcliffe, 2009; Story, Mays, \& Bishop, 2000), our findings highlight the need to improve the nutrition education programs being delivered to school teachers especially regarding the topic area of daily recommended serving of food groups.

Teachers reported a moderate level of selfefficacy to implement nutrition education activities in their classrooms. Less than three quarters were confident in their ability to teach students about nutrition, how to read food labels, and incorporate lessons about nutrition in daily instruction. Future teacher trainings may want to emphasize skills building to develop nutrition teaching self-efficacy in addition to providing nutrition education. Differences in self-efficacy by demographic characteristics were also observed. For example, teachers of Hispanic race/ethnicity were less likely than teachers of White race/ethnicity to know how to teach students about reading food labels. This finding should be further explored in future studies, especially considering that approximately $75 \%$ of the students these teachers are teaching are Hispanic/Latino. Teachers who are of the same race/ethnicity of the students they teach may have more insight into their students' dietary behaviors and could be of more help to them in influencing healthy nutrition behavior. Thus, increasing teachers' skills to deliver various nutrition topics will be important in future interventions. Recognizing that teachers had different levels of nutrition knowledge and selfefficacy to implement nutrition education in the classroom will be critical when developing topics for future teacher trainings.

\section{Limitations}

This study was based on a convenience sample thus there is the potential for selection bias. Also, questionnaire items were adapted from the Network-LAUSD nutrition education materials and were meant to assess information teachers were expected to teach to students. Given the descriptive nature of the study, measures were not tested for reliability and validity. Future large scale studies using validated instruments are needed. Finally, this study was conducted in one large urban school district and the results may not be generalizable to other schools districts.

Given the size of LAUSD, findings from this study have important implications for nutrition research and the development of future nutrition-based teacher trainings. The low levels of nutrition knowledge are an indication that current efforts to train and educate teachers on nutrition are perhaps falling short of the level needed to effect change in students' dietary behaviors. Additionally, the lack of increase in LAUSD students FV consumption throughout several evaluation cycles supports this finding and emphasizes the need to develop a targeted 
Kinsler, J., Slusser, W., Erausquin, J. T., Thai, C. L., Prelip, M. / Californian Journal of Health Promotion 2012, Volume 10, Issue 1, $118-125$

and comprehensive education program that increases the amount of training teachers receive on standardized nutrition education programming, and takes into account differences in teachers' levels of knowledge and selfefficacy skills (Rafiroiu \& Evans, 2005).

\title{
References
}

Chen, Y.H., Yeh, C.Y., Lai, Y.M., Shyu, M.L., Huang, K.C., \& Chiou, H.Y. (2009). Significant effects of implementation of health-promoting schools on schoolteachers' nutrition knowledge and dietary intake in Taiwan. Public Health Nutrition, 13 (4), 579-588.

Davis, E.M., Cullen, K.W., Watson, K.B., Konarik, M., \& Radcliffe, J. (2009). A fresh fruit and vegetable program involves high school students' consumption of fresh produce. Journal of the American Dietetic Association, 109 (7), 1227-1231.

Heim, S., Stang, J, \& Ireland, M. (2009). A garden pilot project enhances fruit and vegetable consumption among children. Journal of the American Dietetic Association, 109 (7), 1220-1226.

Martin, R.E., Hoover, L.C., Fox, E.A., Lan, W.Y, \& Ahmad, M. (1998). Assessment of nutrition education of secondary Texas teachers. Journal of Family and Consumer Sciences Education, 16 (2), 60-75.

Pérez-Rodrigo, C., Klepp, K.I., Yngve, A., Sjostrom, M., Stockley, L., \& Aranceta, J. (2001). The school setting: An opportunity for the implementation of dietary guidelines. Public Health Nutrition, 4 (2B), 717-724.

Prelip, M., Slusser, W., Thai, C., Kinsler, J., Erausquin, J.T (2011). The effects of a school-based nutrition program diffused throughout a large urban community on attitudes, beliefs, and behaviors related to fruit and vegetable consumption. Journal of School Health, $81(9), 520-529$.

Rafiroiu, A.C., \& Evans, A. (2005). Nutrition knowledge, attitudes, and practices among nutrition educators in the south. American Journal of Health Studies, 20.1, 1-14.

Resnicow, K., Cherry, J., \& Cross, D. (1993). Ten unanswered questions regarding comprehensive school health promotion. Journal of School Health, 63 (4), 171-176.

Soliah, L.A., Newell, G.K., Vaden, A.G. \& Dayton, A.D. (1983). Establishing the needs for nutrition education: II. Elementary teachers' nutrition knowledge, attitudes, and practices. Journal of the American Dietetic Association, 83 (4), 447-453.

Story, M., Mays, R.W., \& Bishop, D.B. (2000). 5-a-day Power Plus: process evaluation of a multicomponent elementary school program to increase fruit and vegetable consumption.

Health Education \& Behavior, 27 (2), 187-200.

\author{
Author Information \\ *Janni Kinsler, $\mathrm{PhD}, \mathrm{MPH}$ \\ UCLA School of Public Health \\ Department of Community Health Sciences \\ Box 951772, 26-071B CHS \\ Los Angeles, CA 90095-1772 \\ Phone: $310-475-6757$ \\ Fax: 310-475-6757 \\ E-mail: janni.kinsler@yahoo.com \\ Wendelin Slusser \\ Department of Community Health Sciences, \\ School of Public Health
}


Kinsler, J., Slusser, W., Erausquin, J. T., Thai, C. L., Prelip, M. / Californian Journal of Health Promotion 2012, Volume 10, Issue 1, $118-125$

Department of Pediatrics, School of Medicine, University of California Los Angeles

Jennifer Toller Erausquin

Duke University

Duke Global Health Institute,

Durham, North Carolina

Chan Le Thai

Department of Communication,

University of California, Santa Barbara

Michael Prelip

Department of Community Health Sciences,

School of Public Health

University of California Los Angeles

* corresponding author 